\title{
CORRECTION
}

\section{Correction to: Magnetic and DC Electrical Properties of Cu Doped Co-Zn Nanoferrites}

\author{
P. Himakar ${ }^{1} \cdot$ N. Murali ${ }^{2}$ (D) D. Parajuli ${ }^{1} \cdot$ V. Veeraiah ${ }^{1} \cdot$ K. Samatha ${ }^{1} \cdot$ Tulu Wegayehu Mammo $^{3}$. \\ Khalid Mujasam Batoo ${ }^{4}$. Muhammad Hadi ${ }^{5}$ Emad H. Raslan ${ }^{5}$. Syed Farooq Adil ${ }^{6}$
}

Published online: 14 April 2021

(c) The Minerals, Metals \& Materials Society 2021

\section{Correction to: Journal of ELECTRONIC MATERIALS https://doi.org/10.1007/s11664-021-08760-8}

In the original online version of the article, Khalid Mujasam Batoo's, Emad H. Raslan's, and Muhammad Hadi's given and family names were transposed. The original article has been corrected.
Publisher's Note Springer Nature remains neutral with regard to jurisdictional claims in published maps and institutional affiliations.

The original article can be found online at https://doi.org/10.1007/ s11664-021-08760-8.

N. Murali

muraliphdau@gmail.com

$\triangle$ Khalid Mujasam Batoo

kbatoo@ksu.edu.sa

1 Department of Physics, Andhra University, Visakhapatnam, Andhra Pradesh, India

2 Department of Engineering Physics, AUCE (A), Andhra University, Visakhapatnam, India

3 Department of Physics, CNCS, Aksum University, Axum, Ethiopia

4 King Abdullah Institute for Nanotechnology, King Saud University, P.O. Box-2455, Riyadh 11451, Saudi Arabia

5 Department of Physics, College of Science, King Saud University, P.O. Box-2455, Riyadh 11451, Saudi Arabia

6 Department of Chemistry, College of Science, King Saud University, P.O. Box-2455, Riyadh 11451, Saudi Arabia 